\title{
Knowledge and awareness on usage of mouth masks among dental fraternity during this pandemic COVID-19: A cross-sectional study
}

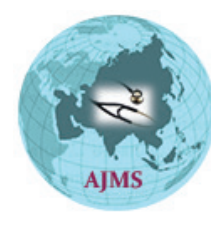

\author{
Ravichandra Ravi ${ }^{1}$, Srividya Athkuri ${ }^{2}$, Charishma Chowdary Ponugubati ${ }^{3}$, \\ Roopesh Borugadda ${ }^{4}$, Sahithi Pamidimukkala ${ }^{5}$, Abdul Afraaz ${ }^{6}$ \\ ${ }^{1,4}$ Associate Professor, Department of Conservative Dentistry and Endodontics, GITAM Dental College \& Hospital, \\ Rushikonda, Visakhapatnam, Andhra Pradesh, India, ${ }^{2}$ Assistant Professor, Department of Conservative Dentistry \\ and Endodontics, GSL Dental College \& Hospital, Rajhmundry, Andhra Pradesh, India, ${ }^{3}$ Post graduate, Department \\ of Periodontics and Oral Implantology, GITAM Dental College and Hospital, Rushikonda, Visakhapatnam, Andhra \\ Pradesh, India, 5,6Post Graduate, Department of Conservative Dentistry and Endodontics, GITAM Dental College \& \\ Hospital, Rushikonda, Visakhapatnam, Andhra Pradesh, India
}

A B S TR A C T

Background: The pandemic caused by novel coronavirus (SARS-CoV-2) in Wuhan, China, in December 2019 is a highly infectious disease. The World Health Organization (WHO) has declared the outbreak of Corona Virus Diseases (COVID 19) as a global public health emergency. Currently, research on novel coronaviruses is still in the primary stage. Aims and Objective: The aim of this study is to assess knowledge and awareness on the usage of mouth masks among dental fraternity during this pandemic COVID-19. Materials and Methods: A total of 507 dentists from the Andhra Pradesh (India) region completed a questionnaire-based survey on knowledge, awareness, and infection control measures, such as usage of mouth masks during the pandemic COVID -19 . The questionnaire was tailored from the guidance and the information provided for healthcare workers issued by the US Centres for Disease Control and Prevention (CDC). A suitable sampling method was used for the collection of data, and the distribution of responses was presented as percentages. Explanatory statistics were performed for all groups based on the percentage of correct responses. Results: A total of 530 participated in the survey, out of which 507 dentists completely answered the survey, and the response rate was 95.6\%. Among the respondents, general practitioners and postgraduates accounted for $58.8 \%$ and $41.2 \%$, respectively. There was a statistically significant difference for all the questions solicited among the respondents. General or private practitioners seem to be more aware than postgraduates, as they have answered correctly ( $>65 \%$ ) for almost all the questions. Conclusion: The inputs from the study help us to throw some light and fill up space where required. There is a specific and strong need to implement periodic educational programmes and training sessions on infection control practices for COVID-19 among dentists in particular.

Key words: Awareness; Covid-19; Questionnaire; Survey

\section{INTRODUCTION}

In the event of any pandemic such as severe acute respiratory syndrome (SARS), it is likely that antiviral drugs and vaccines will be in short supply or that delivery could be delayed. Therefore, non-pharmaceutical interventions such as usage of mouth masks, hand washing, and other hygiene measures might be effective as early control strategies. ${ }^{1}$ Medical masks are a type of personal protective equipment used to prevent the spread of respiratory infections. These masks cover the mouth and nose of the wearer and, if worn properly, may be 
effective at helping prevent transmission of respiratory viruses and bacteria. ${ }^{2}$

Various devices are used in healthcare and community settings worldwide, ranging from cloth, cotton, or gauze masks (cloth masks); medical, surgical, or procedure masks (medical masks); and N95, N99, N100, P2, P3, FFP2, and FFP3 respirators (respirators). The difference between the products arises from their design and intended use. Medical masks and cloth masks (hereafter "facemasks") were designed to prevent the spread of infection from wearers to others but are commonly used to protect the wearer from splashes or sprays of blood or body fluids. Dentists are more prone to get contracted due to Face-to-face communication with the patients and also due to consistent exposure to blood and saliva which predisposes the dental care workers at a greater risk for 2019-nCoV infection. Accordingly, dental practice setup can be a more potential risk for dentist and clinic staff, and there will be a high risk of cross-infection also. ${ }^{3}$

Face masks greatly reduce the risk of dental care workers inhaling aerosols from patient airways, which can contain pathogenic microorganisms related to diseases ranging from influenza to tuberculosis, meningitis or even severe acute respiratory syndrome, and large quantities of saliva, microorganisms, blood, tooth particles and restorative materials. ${ }^{4}$ It can also be transmitted indirectly either through contaminated needle stick injury or improper handling and contact with unsterilized instruments. According to the guiding principles of $\mathrm{CDC}$, it is mandatory to wear face masks, eyewear, gloves, properly disinfected clothes and use adequate high-speed suction while using high- and low-speed rotary instruments. One of the infection control measures is the routine use of face masks. Therefore, dental practitioners and clinical auxiliary staff must wear suitable fluid-resistant masks. However, there is evidence that DHCPs (dental health care professionals) have inadequate knowledge, negative attitudes and poor practices regarding infection control measures. ${ }^{5}$

The objective of this study was to investigate knowledge and awareness about the usage of mouth masks among dental fraternity (general practitioners and postgraduates) in Andhra Pradesh (India). This was a questionnaire-based survey and was tailored from the guidance and information for healthcare workers issued by the US Centres for Disease Control and Prevention (CDC).

\section{MATERIALS AND METHODS}

\section{Participants and procedure}

A descriptive cross-sectional study was conducted between 02-06-2020 and 25-06-2020 among practitioners and post graduates in the state of Andhra Pradesh on knowledge and awareness on usage of mouth masks in the form of a questionnaire.

\section{Questionnaire}

Initially, the questionnaire was distributed to a group of ten post graduate students as a pilot study to evaluate their understanding of the questions. After student feedback, amendments were made to the questionnaire. A total of 18 questions were prepared in Google Docs on knowledge and usage of mouth masks, and an online survey was conducted. They were sent to a total of 530 participants, including practitioners and post graduates. The information obtained during the data collection was strictly kept confidential. The inclusion criteria for the study were post graduates and general practitioners who were practicing.

\section{Sampling method}

The convenient sampling method was used for data collection, and the distribution of responses was presented as frequency and percentages. Sub-groups were classified based on the profession (post graduates and general practitioners).

\section{Statistical analysis}

The data were tabulated in Excel, and descriptive statistics and Pearson chi square tests were performed. Pearson chi square test was used to evaluate the correlation between the application of facemasks with dental students and dental practitioners. The software used for statistical analysis was SPSS version 3.

\section{RESULTS}

A total of 507 participants returned the questionnaire by responding to all the questions. Among those 507 participants, 298 participants (58.8\%) were practitioners, and 209 participants (41.2\%) were post graduate students. When inquired regarding the type of masks preferred during aerosol generation procedures, 218 participants $(43 \%)$ answered as N95 masks, and among which , 50.9\% were practitioners and $49.1 \%$ were post graduate students. A 3 ply mask/surgical mask over N95 were chosen by 142 participants $(28.0 \%)$, of which $70.4 \%$ were practitioners and $29.6 \%$ were post graduates. A statistically significant difference was observed with a $\mathrm{p}$ value of 0.001 . Likewise, when inquired about the type of masks preferred during non-aerosol generation procedures 154 participants (30.4\%) opted for $\mathrm{N} 95$ masks and practitioners $(57.1 \%)$ and post graduates $(42.9 \%)$. A total of $118(23.3 \%)$ preferred to use 3 ply masks, of which $50.0 \%$ were practitioners and $50.0 \%$ were post graduates.A statistically significant difference was observed with a $\mathrm{p}$ value of 0.000 .

When queried whether, during the Covid-19 Pandemic, level 2 and level 3 masks can be used while treating low-risk patients, 360 participants $(71.0 \%)$ had answered as yes, and among them, $66.1 \%$ were practitioners and $33.9 \%$ were 
post graduates. The remaining 147 participants (29\%) had answered it, as No which included $40.8 \%$ of practitioners and $59.2 \%$ of post graduates. A statistically significant difference was observed with a $\mathrm{p}$ value of 0.000 . (Table 1 )

When questioned regarding the use of level 1 masks, 51 participants (10.1\%) opted during Restorative/Endodontic procedures/Tooth preparation procedures, and among them, $47.1 \%$ were practitioners and $52.9 \%$ were post graduates. A total of 252 participants (49.7\%) opted for all of the above, and among them, $66.3 \%$ were practitioners and $33.7 \%$ were post graduates. A statistically significant difference was observed with a $\mathrm{p}$ value of 0.000 .Along with it when the participants were questioned about which layer acts as a filter/barrier, only 327 participants (64.5\%) answered it as the middle layer, of which $55.7 \%$ were practitioners and $44.3 \%$ were post graduates.

When the study population was inquired about changing the mouth masks for every patient, $71.4 \%$ (362) said yes.
Similarly, when questioned whether the cloth masks and surgical masks are as effective as N95 respirators, $81.1 \%$ (411) disagreed to the question.(Table 1).Regarding the type of mask with the best filter capacity of the particles (i.e., 0.3 microns or larger), $55.1 \%$ of practitioners and $44.9 \%$ of post graduates with a total of $53.6 \%(272)$ answered it as FFP3. A total of 175 participants (34.5\%) answered FFP2, and 60 participants answered FFP1.

When the participants were queried about the filter capacity of the FFP3 masks, only $46.7 \%$ of the participants (237) answered $99-99.95 \%$ with a frequency of $57.4 \%$ of practitioners and $42.6 \%$ of post graduates.89.0\% (451) of the participants dispose their mask immediately after removing it with a frequency of $58.5 \%$ of practitioners and $41.5 \%$ of post graduates. (Table 1 )

When we questioned regarding the color code of the bag used for disposal of mask, $64.9 \%$ of the participants opted yellow with a p-value of 0.660 , which indicates

\begin{tabular}{|c|c|c|c|c|}
\hline \multirow[t]{2}{*}{ Question } & \multirow[t]{2}{*}{ Options } & \multicolumn{2}{|c|}{ Occupation in percent } & \multirow[t]{2}{*}{ P-Value } \\
\hline & & General Practitioner & Post Graduate & \\
\hline \multirow{4}{*}{$\begin{array}{l}\text { 1. During aerosol generation procedures } \\
\text { which type of masks are preferred? }\end{array}$} & N 95 masks & $50.9 \%$ & $49.1 \%$ & \multirow[t]{4}{*}{0.001} \\
\hline & 3ply cloth masks & $57.1 \%$ & $42.9 \%$ & \\
\hline & Surgical mask & $82.6 \%$ & $17.4 \%$ & \\
\hline & Combination of any two of the above & $53.3 \%$ & $46.7 \%$ & \\
\hline \multirow{6}{*}{$\begin{array}{l}\text { 2. During non-aerosol generation } \\
\text { procedures which type of masks are } \\
\text { preferred? }\end{array}$} & N 95 masks & $57.1 \%$ & $42.9 \%$ & \multirow[t]{6}{*}{0.000} \\
\hline & 3ply cloth masks & $50.0 \%$ & $50.0 \%$ & \\
\hline & Surgical mask & $57.8 \%$ & $42.2 \%$ & \\
\hline & Combination of any two of the above & $31.7 \%$ & $68.3 \%$ & \\
\hline & Surgical mask over N95 & $93.8 \%$ & $6.3 \%$ & \\
\hline & N95 mask over surgical mask & $95.2 \%$ & $4.8 \%$ & \\
\hline \multirow{2}{*}{$\begin{array}{l}\text { 3. Do you think that, during Covid-19 } \\
\text { pandemic, level } 2 \text { and level } 3 \text { masks can } \\
\text { be used while treating low risk patients? }\end{array}$} & Yes & $66.1 \%$ & $33.9 \%$ & \multirow[t]{2}{*}{0.000} \\
\hline & No & $40.8 \%$ & $59.2 \%$ & \\
\hline \multirow[t]{4}{*}{$\begin{array}{l}\text { 4. When will you prefer to use level }-1 \\
\text { masks? }\end{array}$} & $\begin{array}{l}\text { Restorative/endodontic procedures / } \\
\text { tooth preparation procedures }\end{array}$ & $47.1 \%$ & $52.9 \%$ & \multirow[t]{4}{*}{0.000} \\
\hline & $\begin{array}{l}\text { Post insertion reviews for removal } \\
\text { prostheses }\end{array}$ & $42.7 \%$ & $57.3 \%$ & \\
\hline & During surgical procedures & $78.0 \%$ & $22.0 \%$ & \\
\hline & All the above & $66.3 \%$ & $33.7 \%$ & \\
\hline \multirow{3}{*}{$\begin{array}{l}\text { 5. In a three layered mask, which layer } \\
\text { acts as a filter/barrier? }\end{array}$} & First Layer & $61.5 \%$ & $38.5 \%$ & \multirow[t]{3}{*}{0.035} \\
\hline & Middle Layer & $55.7 \%$ & $44.3 \%$ & \\
\hline & Inner Layer & $78.1 \%$ & $21.9 \%$ & \\
\hline \multirow{2}{*}{$\begin{array}{l}\text { 6. Do your prefer changing your mask for } \\
\text { every patient? }\end{array}$} & Yes & $56.4 \%$ & $43.6 \%$ & \multirow[t]{2}{*}{0.080} \\
\hline & No & $64.8 \%$ & $35.2 \%$ & \\
\hline \multirow{2}{*}{$\begin{array}{l}\text { 7. Do you think surgical masks and } 3 \text { ply } \\
\text { cloth masks are equally effective to } \\
\text { N95 respirators? }\end{array}$} & Yes & $62.5 \%$ & $37.5 \%$ & \multirow[t]{2}{*}{0.410} \\
\hline & No & $57.9 \%$ & $42.1 \%$ & \\
\hline \multirow{2}{*}{$\begin{array}{l}\text { 8. Which type of mask among the three } \\
\text { will have the best filter capacity of the } \\
\text { particles (i.e } 0.3 \text { microns or larger)? }\end{array}$} & FFP1 & $65.0 \%$ & $35.0 \%$ & \multirow[t]{2}{*}{0.189} \\
\hline & FFP2 & $62.3 \%$ & $37.7 \%$ & \\
\hline \multirow{3}{*}{$\begin{array}{l}\text { 9. How much is the filter capacity } \\
\text { (removes } \mathrm{x} \% \text { of all the particles that are } \\
0.3 \text { microns in diameter or larger) of the } \\
\text { FFP3 masks? }\end{array}$} & $99.97 \%$ & $52.2 \%$ & $47.8 \%$ & \multirow{3}{*}{0.000} \\
\hline & $99 \%$ & $87.5 \%$ & $12.5 \%$ & \\
\hline & Less than 99 percent & $54.5 \%$ & $45.5 \%$ & \\
\hline \multirow{2}{*}{$\begin{array}{l}\text { 10. Do you dispose your mask immediately } \\
\text { after removing it? }\end{array}$} & Yes & $58.5 \%$ & $41.5 \%$ & \multirow[t]{2}{*}{0.755} \\
\hline & No & $60.7 \%$ & $39.3 \%$ & \\
\hline
\end{tabular}


no statistically significant difference (Table 2). When surveyed regarding fogging of the eye wear, 43.4\% (220) of participants said that they experienced more fogging with 3 ply masks with frequencies of $42.3 \%$ and $57.7 \%$ of practitioners and post graduates, respectively.

When the side effects of usage of masks wereinquired, $76.1 \%$ (386) of participants answered as yes, and 79.1\% (401) of the study population accepted that there will be a reduction in $\mathrm{O}_{2}$ and $\mathrm{Co}_{2}$ levels with prolonged use of masks. A total of $67.1 \%$ (340) of participants agreed that there will be a reduction in transmission of various infections such as SARS CoV with use of masks. Regarding the use of N95 respirators among the general public, $57.0 \%$ (289) of the participants did not support their use, while $43.0 \%$ (218) of the participants supported its use.

When a question was asked as to which mask is suitable for COVID-19 patients, 50.7\% (257) of the participants answered as valved N95, and the remaining 49.3\% (250) of the participants advised the usage of non-valved N95 masks, among which $56.8 \%$ were practitioners and $43.2 \%$ were post graduates. When a question was asked about the first person who suggested wearing a mouth mask in 1897 , only $57.2 \%$ (290) of the participants answered correctly as Johann Mikulicz with frequencies of $53.4 \%$ and $46.6 \%$ for practitioners and post graduates, respectively, with a $\mathrm{p}$-value of 0.000 , which shows a significant difference. (Table 2)

\section{DISCUSSION}

Face masks are used in the public in Asian countries not only to guard people from acquiring respiratory infection but also to decrease the spread of disease from the wearer. Such use often increases during outbreaks and pandemics. Usually, masks are made of different materials and with specific designs depending on the filtering capacity. Various standards are used during evaluating the masks in the health care setting because the main aim of preparing the masks is to protect the wearer from infectious particles. Masks not only protect the wearers but also protect the others by blocking the droplets ejected by the wearer while speaking and coughing. Therefore, keeping in mind, the purpose of our paper is to evaluate the knowledge on the masks among dental fraternity, especially general practitioners and post graduates. The two segments of dentists are more prone to become infected while treating patients in pandemics or outbreaks such as COVID 19.

According to the US CDC, close contact is defined as "being within approximately 6 feet $(2$ meters) of a COVID-19 case for a prolonged period of time or having direct contact with infectious secretions of a COVID-19 case. Likewise, several additional significant explanations have been stipulated and issued by the $\mathrm{CDC}{ }^{7}$

This group (Dentists) has the highest risk of potential contact with the virus because they will be having near patient interaction at some point in the healthcare setting and consequently at risk of contracting and smattering the

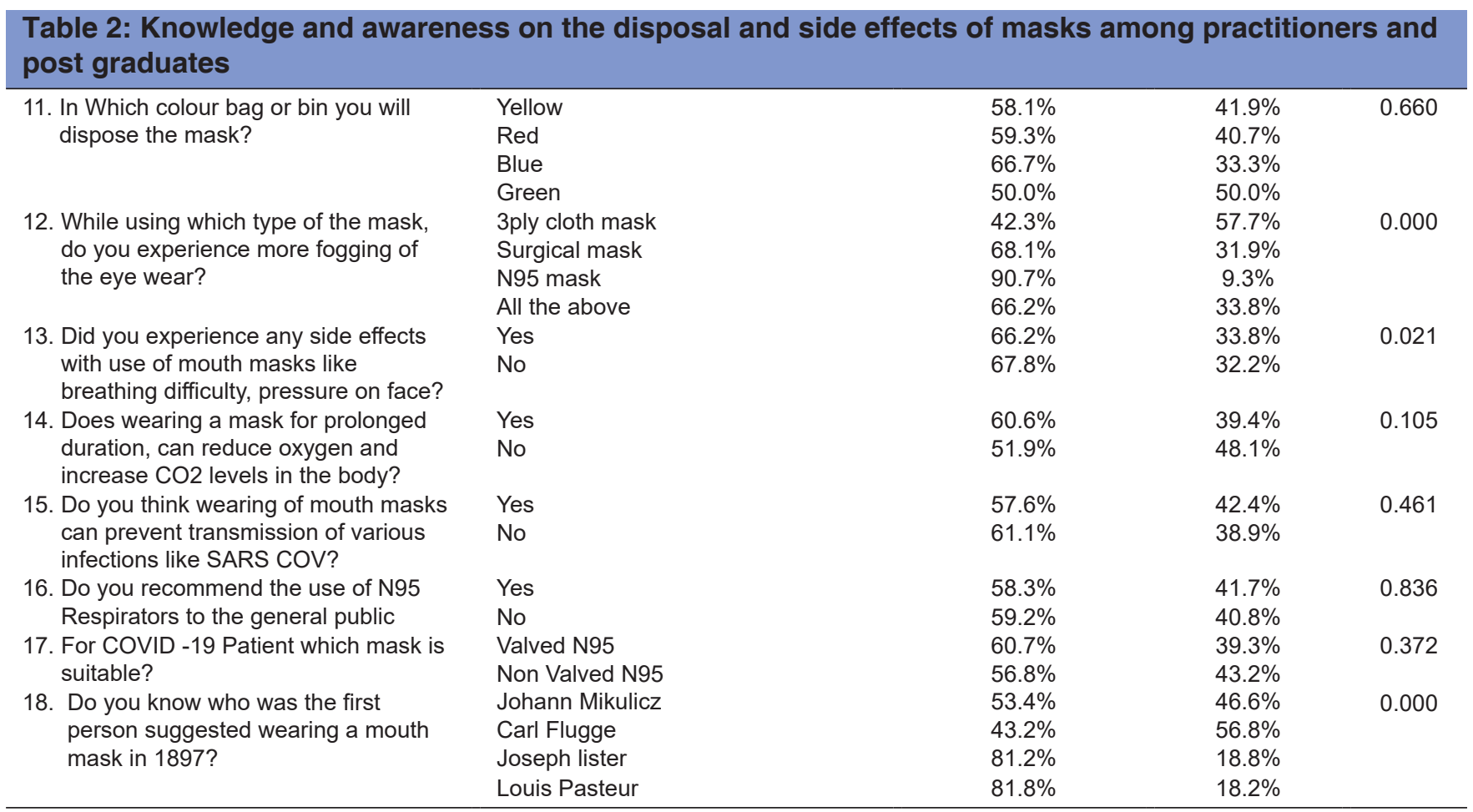


contagion. A mixed response was noted about the usage of masks during the aerosol and non-aerosol generating procedures, but the maximum percentage was general dentists, and post graduates mentioned that surgical masks were used over the N95 while performing these types of procedures. This is in accordance with the stand-in exposure studies; N95 respirators were associated with less filter penetration, less face-seal leakage and less total inward leakage under laboratory investigational conditions compared with surgical masks. Although N95 respirators appeared to have a shielding advantage over surgical masks in the laboratory setting, the meta-analysis showed that there were inadequate data to definitively determine whether N95 respirators are superior to surgical masks in protecting health care workers against transmissible acute respiratory infections in clinical settings. ${ }^{8,9}$

In a recent systematic review and meta-analysis regarding surgical masks versus N95 respirator masks by the Chinese Cochrane Center, which includes six randomized controlled trials with a total of approximately 9171 health care workers, there was no difference in the efficacy between surgical and N95 masks in preventing laboratory-confirmed influenza or respiratory viral infections. ${ }^{9}$ These studies provide some confidence that the surgical masks may help as well as N95 masks in a health care setting, but we have to follow proper protocols during wearing and removing these masks along with following adequate hand hygiene measures. ${ }^{10}$

Regarding the usage of level 1, 2 and level 3 masks, according to ADA-specified guide lines, level 1 masks are not widely used in dental practice, and they are appropriate only when there is no risk of blood or body splash. These can be used when conducting post-insertion reviews for removable prostheses, mouth guards and removable appliances and other performing orthodontic adjustments. Regarding the usage of level 2 masks, these are most commonly used in dental practice due to their ability to block the particle sizes commonly encountered in the dental setting or practice. These masks will block aerosols of three microns or less in size, which arises from procedures such as restorative and endodontic procedures, periodontal procedures such as the use of ultrasonic scalars and air-turbine hand pieces. Coming to the level 3 masks, these have a high level of splash protection and are used for procedures where there is a greater risk for exposure to blood and body fluids such as surgical and trauma procedures. ${ }^{11}$

Surgical masks used for dental purposes are fluid-repellent paper filter masks, and they are suitable for both surgical and nonsurgical procedures to generate aerosols. The filtration ability of the masks starts declining with moisture on the inner and outer surfaces of the mask after approximately 20 minutes. It is difficult to change masks during long surgical procedures and is not necessary unless the mask becomes completely wet from within or without. ${ }^{12}$
N95 masks and the other respirators are available with valve and without a valve. The valve $\mathrm{N} 95$ masks are not suitable for patients suffering from COVID-19 because exhalation allows the virus to pass easily and can potentially infect adjacent or neighboring persons. ${ }^{12,13}$

When coming to the three-layered mask whose layer acts as a filter, there is a mixed response, 50 percent of general dentists and 49 percent of post graduates answered correctly that the middle layer acts as a filter. This is in accordance with Jagadeesh kumar et al., who found that the outer layer is hydrophobic and is a fluid-repelling layer, and the main function of this layer is to prevent germs from attaching to it. When coming to the inner layer, it is a hydrophilic layer that absorbs any kind of moisture from the air that we exhale. There is a middle layer that is very important and actually filters microorganisms. ${ }^{13}$

When the participants were questioned about the disposal of the masks in which color bags, 58 percent of general practitioners and 41.9 percent of postgraduates answered correctly that they would dispose in yellow color bags, and the rest of all participants answered differently. When coming to the disposal of the mask immediately after every patient, 58.5 percent of general practitioners and 41.5 percent of postgraduates answered yes, and instant discarding of the mouth mask decreased the spread of infection from the patient to the patient as well as to the dentist; these practices are supposed to be practiced by every dentist in the clinical care setting to prevent cross contamination. ${ }^{5}$ General dentists are more aware when compared to postgraduates, it may be due to more years of experience in the clinical practice than the post graduates.

When we enquired about whether they felt difficulty breathing while wearing a mouth mask, $76.1 \%$ had problems breathing while wearing the mouth mask, which might be due to thick barriers provided by the manufacturing companies. ${ }^{5}$

A total of $57.6 \%$ and $42.4 \%$ of the practitioners and post graduates, respectively, agreed that there will be a reduction in the transmission of various infections, such as SARS CoV, as wearing mouth masks can prevent community spread. ${ }^{14}$ According to Kumar J et al., there is insufficient evidence supporting this hypothesis because along with the usage of masks, hand hygiene and infection control protocols should be followed, which may help to prevent disease transmission. ${ }^{13}$

For the type of mask with the best filter capacity of the particles (i.e., 0.3 microns or larger), $55.1 \%$ of practitioners and $44.9 \%$ of post graduates answered correctly as FFP3. Only $46.7 \%$ of the participants (237) answered its filter capacity correctly as $99-99.95 \% .{ }^{15}$ 


\section{CONCLUSION}

The inputs from the survey show that there is a strong need to implement periodic educational interventions and training programs on infection control practices or about the usage of protective equipment during this pandemic crisis among dentists in particular. Conducting regular educational webinars with customary guidelines and contents to create more awareness amongst dental fraternity is important for them to stay safe and protect our society from transmissible diseases such as COVID-19.

\section{ACKNOWLEDGEMENT}

The authors take this opportunity to thank all the participants of the study.

\section{REFERENCES}

1. Maclntyre CR, Epid MA, Cauchemez S, Dwyer DE, Seale H, Cheung $\mathrm{P}$, et al. Face mask use and control of respiratory virus transmission in households. Emerg Infect Dis. 2009; 15(2): 233-241. https://doi.org/10.3201/eid1502.081166

2. Desai $A N$ and Mehrotra P. Medical Masks. JAMA. 2020; 323(15):1517-1518

https://doi.org/10.1001/jama.2020.2331

3. Fallahi HR, Keyhan SO, Zandian D, Kim SG and Cheshmi B. Being a front-line dentist during the Covid-19 pandemic: a literature review. Maxillo fac Plast Reconstr Surg. 2020; 42(12):1-9. https://doi.org/10.1186/s40902-020-00256-5

4. Checchi L, Montevecchi M, Moreschi A, Graziosi F, Taddei P and Violante FS. Efficacy of three face masks in preventing inhalation of airborne contaminants in dental practice. J Am Dent Assoc. 2005; 136(7):877-882.

https://doi.org/10.14219/jada.archive.2005.0288

5. Vinita Mary A, Kesavan R, Teenu Lakshmi V, Thamilazhagi S and Vaishnavi K. Knowledge and practices about mouth masks among dental students in Chennai city - a cross sectional descriptive study. JIDAM. 2019; 6(4):117-124.
6. Maclntyre CR and Chugtai AA. Facemasks for the prevention of infection in healthcare and community settings BMJ. 2015; 350:h694.

https://doi.org/10.1136/bmj.h694

7. Frequently asked questions about hand hygiene for healthcare personnel responding to COVID-2019.(2020):https://www.cdc. gov/coronavirus/2019-ncov/infection control/hcp hand-hygienefaq.html

8. Smith JD, MacDougall CC, Johnstone J, Copes RA, Schwartz B and Garber GE. Effectiveness of N95 respirators versus surgical masks in protecting health care workers from acute respiratory infection: a systematic review and meta-analysis. CMAJ. 2016; 188(8):567-574.

https://doi.org/10.1503/cmaj.150835

9. Johnson DF, Druce JD, Birch C and Grayson ML. A quantitative assessment of the efficacy of surgical and N95 masks to filter influenza virus in patients with acute influenza infection. Clin Infect Dis. 2009; 49(2):275-277.

https://doi.org/10.1086/600041

10. Long Y, Hu T, Liu L, Chen R, Guo Q, Yang L, et al. Effectiveness of N95 respirators versus surgical masks against influenza: $A$ systematic review and meta-analysis. J Evid Based Med. 2020; 13(2):93-101.

https://doi.org/10.1111/jebm.12381

11. Which Mask and When. ADA guidelines for infection control: Last updated on April 7 2020. https://www.ada.org.au/WhichMask-And-When

12. Advice on the use of masks in the context of COVID-19: Interim guidance, 5 June 2020 (WHO/2019-nCov/IPC_Masks/2020.4). https://apps.who.int/iris/handle/10665/332293

13. Kumar J, Katto MS, Siddiqui AA, Sahito B, Jamil M, Rasheed N, et al. Knowledge, Attitude, and Practices of Healthcare Workers Regarding the Use of Face Mask to Limit the Spread of the New Coronavirus Disease (COVID-19). Cureus. 2020;12(4):e7737. https://doi.org/10.7759/cureus.7737

14. Howard J, Huang A, Li Z, Tufekci Z, Zdimal V, vander WH, et al. Face Masks Against COVID-19: An Evidence Review. Preprints 2020, 2020040203. https://doi.org/10.20944/preprints202004.0203.v3

15. St. Paul MN. Respirators and surgical masks: comparison, $3 \mathrm{M}$ occupational health and environmental safety division. http:// multimedia.3m.com $/ \mathrm{mws} / \mathrm{media} / 957730 \mathrm{O} /$ respirators-andsurgical-masks-contrasttechnical-bulletin.pdf Accesed:15 thjuly 2020

\footnotetext{
Author's contributions:

RR-Concept and design of the study; interpreted the results, prepared first draft of manuscript and critical revision of the manuscript; SA- Statistically analyzed and interpreted; reviewed the literature and manuscript preparation; CCP-Design of the study, statistically analyzed and interpreted, preparation of manuscript and revision of the manuscript; RB-Concept reviewed the literature and manuscript preparation. SP-Prepared first draft of manuscript and critical revision of the manuscript; AA- Statistically analyzed and interpreted.

Work attributed to:

GITAM Dental College \& Hospital, Rushikonda, Visakhapatnam, Andhra Pradesh, India.

Orcid ID:

Dr Ravichandra Ravi - (D) https://orcid.org/0000-0002-4099-3938

Dr. Srividya Athkuri - (i) https://orcid.org/0000-0001-8307-0802

Dr. Charishma Chowdary Ponugubati - (1) https://orcid.org/0000-0002-8230-9655

Dr. Roopesh Borugadda - (1) https://orcid.org/0000-0002-3835-3392

Dr. Sahithi Pamidimukkala - (1) https://orcid.org/0000-0002-6885-784X

Dr. Abdul Afraaz - (1) https://orcid.org/0000-0001-7034-7446

Source of support: None, Conflicts of Interest: None.
} 